Original Article

Journal of Epilepsy Research pISSN 2233-6249 / eISSN 2233-6257

Received March 14, 2019

Revised June 20, 2019

Accepted June 28, 2019

Corresponding author:

Akanksha Rani, MPhil

Department of Psychiatric Social Work,

National Institute of Mental Health and

Neurosciences, Govindswamy Building,

Hosur Road, Near Bangalore Milk Dairy,

Bangalore 560 029, India

Tel. +91-9573964312

E-mail; akanksha.rani89@gmail.com

\section{Parental Knoweldge, Attitude, and Perception about Epilepsy and Sociocultural Barriers to Treatment}

\author{
Akanksha Rani, MPhil, Priya Treesa Thomas, PhD \\ Department of Psychiatric Social Work, National Institute of Mental Health and Neurosciences, Bengaluru, India
}

Background and Purpose: The present study focused on assessing parental knowledge, attitudes, and perceptions about epilepsy as well as addressing the socio-cultural barriers to its treatment.

Methods: Data were collected from out-patient consultations in the neurology department of a tertiary referral center in South India. Parents of sixty children suffering from epilepsy in the age-group of 4-15 years were interviewed to explore their knowledge, attitudes, and perceptions about epilepsy. They were recruited in 2015 over a consecutive period of six months. The tools administered were: socio-demographic schedule; clinical profile; a knowledge, attitude, and perception questionnaire prepared by the researcher; and a few case studies with psychosocial interventions.

Results: The mean age of the parents who brought their children to the hospital was 37.2 years, with $71.7 \%$ being male, of which, $36 \%$ were educated up to secondary/intermediate level and were of lower socio-economic status. The mean age of the children with epilepsy was 8.4 years with $66.7 \%$ of them being male. Among them, $50 \%$ had the most commonly occurring generalized seizures and $26.7 \%$ had the co-morbid condition of cerebral palsy. Around $37.7 \%$ parents attributed the seizures to evil spirits or supernatural powers, $52.5 \%$ to mental illness, and $72.1 \%$ were influenced by their families to initially seek religio-spiritual or traditional treatment in desperation for a cure of the illness. In total, $91.8 \%$ of the parents visited holy places, made "mannats", or prayed in worship for hours for their child's recovery. Conclusions: Creating awareness about epilepsy is important to address the socio-cultural barriers to its treatment and improve help-seeking behavior. (2019;9:65-75)

Key words: Parents, Child, Epilepsy, Sociocultural barriers

\section{Introduction}

Epilepsy is the most common childhood neurological disorder. Children who suffer from seizures tend to have significant psychosocial difficulties that are more noticeable when seizures coexist with other chronic disorders. A pediatric epilepsy study carried out in Mumbai found that $55.3 \%$ children had partial seizures while 27\% had generalized seizures. ${ }^{1}$ In a study on 123 children with refractory epilepsy, it was found that children whose onset was below the age of two years were mostly males with co-morbid neurological or psychiatric conditions with a certain seizure type acting as a risk factor for refractoriness. ${ }^{2}$ Children with epilepsy have other co-existing health conditions that significantly affect their health and intensifies their parents' worries and anxiety as they require continued surveillance and are often in a state of uncertainty and apprehension. While scientific advances have led to early identification and treatment for epilepsy, misconceptions about its causes and lack of awareness about safety and injury prevention still exist. ${ }^{3}$

Socio-cultural barriers are manifested in the form of negative attitudes and discrimination against persons with epilepsy due to causation beliefs that play an important role in treatment choices made by persons with epilepsy and their families. ${ }^{4}$ Multiple studies have shown that treatment choices are affected by social and demographic factors such as income, education, age, gender, social network, and distance traveled by an individual from the treatment location. ${ }^{5}$

Help-seeking behavior of parents of children with epilepsy is influenced by their religious and cultural beliefs that also affect their epilepsy management skills. In African counties, epilepsy is believed to be caused by spirits, witchcraft, poisoning, and regarded as a contagious disease leading to social isolation of persons affected with it. ${ }^{6}$ A study reported that traditional healing practices are considered the 
first line of treatment for childhood epilepsy because such services are provided in local communities by someone known to the family, that makes the family more comfortable in discussing their child's condition. Traditional healers also provide support and acceptance through flexible systems of payment that allow the family to pay through alternative means or in installments. ${ }^{7}$ One of the studies reported that in developing countries around $80 \%$ of persons with epilepsy lacked western medication and sought help from traditional healers, religious institutes, and others. ${ }^{8}$

Parents' knowledge, attitudes, and perceptions about epilepsy get affected by the severity of their child's seizures. One of the studies reported that the more severe the child's seizure was, the poorer the parent's knowledge, attitude, and perception was, which resulted in their feeling more stigmatized and socially isolated. ${ }^{9}$ Perception of parents about their child's epilepsy affects the child's relationships with family, peers, and siblings; social activities; development of the child's self-esteem; and the parents' hope for their child's future. All these factors were related to seizure frequency, total number of medications taken, consultations done in a year, and nights spent in the hospital because of the child's severe condition. ${ }^{10}$

The current study highlighted how the socio-cultural belief system on epilepsy affects knowledge, attitude, and perception of parents of children with epilepsy, which in turn impacts their treatment-seeking behavior.

\section{Objectives of the Study}

To understand the knowledge, attitude, and perception of parents of children with epilepsy before seeking treatment; to assess the relationship between seizure severity and the knowledge, attitude, and perception of parents; to develop guidelines for addressing socio-cultural barriers to treatment and improve knowledge, attitude, and perception of parents.

\section{Methods}

\section{Research design}

The study used a descriptive research design. To illustrate the findings from this part of the study, two case studies were used.

\section{Setting and sampling}

Data were collected from out-patient consultations in the neurology department of a tertiary referral center in South India. The sample size was determined through a pilot study and previous studies.
Sixty parents of children with epilepsy were recruited, who attended the out-patient services regularly and met exclusion and inclusion criteria consecutively.

\section{Participants}

The participants' were 18 years of age or older, having children affected by generalized or partial seizures in the 4-15 age-group. Parents of children with co-morbid diagnosis of attention deficit hyperactivity disorder, autism, intellectual developmental disorder (IDD)/mental retardation, and cerebral palsy were also included. Children diagnosed with pseudo and febrile seizures, neurodegenerative diseases of infancy and childhood, or any other medical or psychiatric illness were excluded.

\section{Instrumentation}

The researchers compiled socio-demographic profiles of the children and parents that included their background information as well as the children's seizure details by scheduling semi-structured interviews.

Scales ${ }^{10}$ were administered for seizure severity and side-effects. The seizure severity scale focused on consciousness, motor symptoms, incontinence, injuries, pain, and overall severity. The side-effects scale consisted of two subscales: one that measured toxicity, which is severity of medicine dose-related side-effects and another that measured chronicity, the severity of long-term behavioral and cognitive side-effects. The scale's items represented the following areas of content: a good internal consistency (Cronbach's alpha, 0.85 ) and a high test-retest correlation of 0.93 . Scoring determined the mean, that is a value $>2$ standard deviation (SD) and higher than the lowest possible score and a 3 SD that was lower than the highest possible score.

The face and content validation of the knowledge, attitude, and perception questionnaire prepared by the researcher was done by experts in the field comprising three psychologists, three neurologists, three social workers, and three nurses working in the Pediatric Neurology Ward. Their suggestions were incorporated before preparing the questionnaire's final draft.

Experts prepared and validated the guide for the qualitative interviews. It was used to conduct interviews with parents using individualized themes to assess their explanatory model of illness, cultural and religious beliefs, and community practices.

The above findings and themes derived were used to prepare guidelines for addressing socio-cultural barriers to treatment as well 
as to improve knowledge, attitude, and perception of parents having children with epilepsy based on literature search, reviews, and existing cross-cultural guidelines. Experts such as pediatric neurologists, child psychiatrists, psychologists, social workers, and nurses working with children with epilepsy were interviewed and their opinions were also incorporated.

\section{Procedure}

Parents bringing their children with epilepsy for out-patient consultation and who had been coming regularly for follow-up in the last one year to the neurology department of a tertiary referral center in South India during July 2015 to December 2015 were recruited based on their children's medical reports and diagnosis by two independent neurologists. Parents who fitted the inclusion-exclusion criteria were contacted and explained about the nature of the study, confidentiality, and their right to withdraw. Their written consent was taken before they participated in the study. The researcher read out the questions and marked the answers for parents who were illiterate.

The researcher then spent some time with the child and built initial rapport by engaging the child in coloring tasks or solving a puzzle so that the parents could be interviewed.

Parents who were taken for the case studies were seen for 8 to 10 sessions. Personal interviews and observation were used focusing on themes such as their understanding about their child's seizure condition, explanatory models of illness, their cultural beliefs and religious practices, community resources in the form of first line of treatment or alternative treatment modalities that had been utilized before coming to the hospital. Based on the understanding acquired from the assessment, the guidelines for interventions were developed to improve parents' knowledge, attitude, and perception. It included a detailed family psychoeducation module, wherein a medical explanatory model was used to educate parents on epilepsy, address myths and misconceptions related to their child's illness, safety, and injury prevention measures. The intervention also focused on re-orienting parental expectations regarding their child's recovery, addressing inconsistencies in parenting, improving parent-child interactions, providing support and guidance. The module also incorporated supportive psychotherapy by focusing on venting their feelings, concerns, fears, or frustrations and validating and normalizing them. Parents were also helped to adjust in their loss and grief as well as provided support in their respective role change and adaptation efforts. Some relaxation techniques to help them deal with their anxi- ety related to the uncertainty of their child's illness were also discussed with them.

\section{Data analysis}

The data from the questionnaires were analyzed using descriptive statistics like frequency and percentage and non-parametric tests like

Table 1. Socio-demographic profile of parents

\begin{tabular}{|c|c|}
\hline Variable & Value \\
\hline \multicolumn{2}{|l|}{ Age (years) } \\
\hline $25-35$ & $26(43.3)$ \\
\hline $36-45$ & $22(36.7)$ \\
\hline $46-55$ & $12(20)$ \\
\hline \multicolumn{2}{|l|}{ Gender } \\
\hline Father & $43(71.7)$ \\
\hline Mother & $17(28.3)$ \\
\hline \multicolumn{2}{|l|}{ Education } \\
\hline Illiterate & $5(8.3)$ \\
\hline Primary/secondary/higher & $15(25)$ \\
\hline Secondary/intermediate & $22(36)$ \\
\hline Graduate/post graduate & $18(30)$ \\
\hline \multicolumn{2}{|l|}{ Occupation } \\
\hline Unemployed/homemaker & $11(18.3)$ \\
\hline Unskilled & $8(13.3)$ \\
\hline Semi-skilled & $26(43.3)$ \\
\hline Skilled & $15(25.0)$ \\
\hline \multicolumn{2}{|l|}{ Domicile } \\
\hline Urban & $26(43.3)$ \\
\hline Rural & $21(35)$ \\
\hline Semi-urban & $13(21.7)$ \\
\hline \multicolumn{2}{|c|}{$\begin{array}{l}\text { Estimated average monthly family income } \\
\text { (modified Kuppuswamy Scale*) }\end{array}$} \\
\hline RS6,214-RS10,356 & $40(66.7)$ \\
\hline RS10,357-RS15,535 & $18(33.0)$ \\
\hline RS15,536-RS20,714 & $2(3.3)$ \\
\hline \multicolumn{2}{|l|}{ Type of family } \\
\hline Nuclear & $33(55.0)$ \\
\hline Joint & $27(45.0)$ \\
\hline \multicolumn{2}{|l|}{ Primary caregiver } \\
\hline Father & $5(8.3)$ \\
\hline Mother & $51(85.0)$ \\
\hline Others & $4(6.7)$ \\
\hline
\end{tabular}

Values are presented as number (\%).

*Kuppuswamy Scale was used to assess socio-economic status of the participants. The scale was developed in the year 1976 but it's get updated every year. It is overall aggregate income of the whole family pooled from all sources. 
Spearman rho. Using the case study method, selected parents and children were studied in detail and presented through case vignettes. Possible psycho-social interventions and appropriate referrals were provided to the children and their family members.

\section{Ethical considerations}

Ethical clearance was taken from the Institute's Ethics Committee of National Institute of Mental Health and Neuro Sciences (NIMHANS; IRB No.: NIMHANS/IEC/2015) before conducting the study. A written consent was also taken from all the parents prior to their participation in the study. To protect the privacy of all the parents and children who participated in the study, their names were changed and identifying information was excluded.

\section{Results}

\section{Socio-demographic profile of the parents (Table 1)}

The table shows that the majority of the parents were in the 25 to 35 age-group with a mean age of 37.2 years, $71.7 \%$ were males, $36 \%$ were educated up to secondary/intermediate level. Of these, $43.3 \%$ did semi-skilled jobs, $66.7 \%$ had a monthly family income of RS6,000-10,000, 55\% of the children came from nuclear families, and the mother was the primary caregiver for $85 \%$ of the children.

\section{Children's socio-demographic and clinical profile (Table 2)}

Clinical profiles were assessed by reviewing case files and treatment details. The children's mean age was 8.4 years with $40 \%$ being in the 6-10 age-group. The children affected with epilepsy comprised $66.7 \%$ males. The findings also showed that the average number of children had generalized seizures that had been controlled for only $26.7 \%$ of the children. In terms of co-morbid conditions, $26.7 \%$ had cerebral palsy, followed by $16.7 \%$ with IDD. Other associated problems along with seizures were $31.7 \%$ memory problems followed by $23.3 \%$ having difficulty in speech, temper tantrums, and anger outbursts.

\section{Seizure severity in children with epilepsy (Table 3)}

Seizure severity and a side-effects scales ${ }^{10}$ were administered to assess the severity of seizures and the side-effects of anti-epileptic medication. The assessment showed that the maximum number of parents reported that their child had motor symptoms like decreased consciousness, urine incontinence, postictal headache/pain, and tongue biting. Around $52.5 \%$ parents reported that their children resumed normal activity within a few minutes to an hour after a seizure episode. In terms of side-effects of medication, $80.3 \%$ children had toxic side effects like dizziness, $80.3 \%$ had loss of appetite, $73.8 \%$ had chronic side effects like behavioral disturbances, and $68.9 \%$ threw temper tantrums.

\section{Knowledge, attitude, and perception of parents regarding their child's seizure condition (Table 4)}

Assessment of parents' knowledge, through administering questionnaires revealed that of the $96.7 \%$ who had heard about epilepsy, for $37.7 \%$, the source of information had been relatives and friends; $86.9 \%$ had known a person with epilepsy, $82 \%$ knew their child's diagnosis, $52.5 \%$ had misconceptions about seizures being a mental illness, 37.7\% felt it was caused by evil spirits, $44.3 \%$ had poor awareness about safety and injury prevention, were unaware that

Table 2. Socio-demographic and clinical profile of children

\begin{tabular}{lc}
\hline Variable & Value \\
\hline Age & $14(23.3)$ \\
Less than 6 years & $24(40.0)$ \\
Between 6 to 10 years & $22(36.7)$ \\
Greater than 10 years & \\
Gender & $40(66.7)$ \\
Male & $20(33.3)$ \\
Female & \\
Main seizure type & $30(50.0)$ \\
Generalized seizures & $19(31.7)$ \\
Partial seizures & $11(18.3)$ \\
Combination of both generalized and partial & \\
Seizure control & $44(73.3)$ \\
Not controlled & $16(26.7)$ \\
Controlled & \\
Co-morbid condition & $16(26.7)$ \\
Cerebral palsy & $10(16.7)$ \\
Intellectual developmental delay (IDD) & $2(3.3)$ \\
Autism & $2(3.3)$ \\
Attention deficit hyperactivity disorder (ADHD) & $14(23.3)$ \\
Associated problems & \\
No problem & \\
Difficulty in speech & \\
Temper tantrums and anger & $(8.3)$ \\
Memory problems & \\
Combination of any two & \\
Val.3) & \\
\hline
\end{tabular}

Values are presented as number (\%). 
medicines had to be kept out of reach of children and were worried about the side-effects of medicines, while $98.4 \%$ felt that if they missed their follow up date then a double dose of medication would be required till the next follow up. The future risk factors and potential consequences identified included $41 \%$ with memory problems and $27.9 \%$ with difficulty in communication, speech, and comprehension. Parents who responded to their children's seizures by restraining them were $78.7 \%$, while $88.5 \%$ put objects between the teeth, and $96.7 \%$ placed a bunch of keys in their hand, a shoe or an onion on the person's nose, or applied oil.

In terms of attitude, $50.8 \%$ of the parents felt that persons with epilepsy could get married, $63.9 \%$ felt they could have children, $85.2 \%$ had no problem in allowing their child to play with a friend who had epilepsy, $62.3 \%$ encouraged their child to continue schooling despite a seizures disorder, $95.1 \%$ prevented their child from participating in sports activities, only $11.5 \%$ were willing to allow their child to get married to persons with epilepsy, $16.4 \%$ were willing to employ a person with epilepsy, $80.3 \%$ believed that children with epilepsy required more social and practical support for psycho-social development, $72.1 \%$ consulted faith-healers or holy men for treatment, $91.8 \%$ visited holy places or performed "mannat", and $95.1 \%$ had a lot of concern about disclosing their child's illness.

With regard to perception about illness, the average number of parents blamed or considered their child a misfortune when upset,

Table 3. Seizure severity and side-effects of medications for seizures and co-morbid conditions

\begin{tabular}{lc}
\hline Variable & Value \\
\hline Decreased consciousness & $19(31.1)$ \\
Urine incontinence & $18(29.5)$ \\
Motor symptoms & $17(27.9)$ \\
Postical sleep & $10(16.4)$ \\
Postical headache or muscle pain & $15(24.6)$ \\
Tongue bite & $27(44.3)$ \\
Short time taken to resume normal activity & $32(52.5)$ \\
Toxic side-effects & \\
$\quad$ Dizziness and loss of appetite & $49(80.3)$ \\
Constipation and restlessness & $38(62.3)$ \\
Fatigue & $36(59.0)$ \\
Chronic side-effects & \\
$\quad$ Temper tantrums & $42(68.9)$ \\
Decreased concentration & $41(67.2)$ \\
Behavioral disturbances & $45(73.8)$ \\
\hline
\end{tabular}

Values are presented as number (\%).
Table 4. Knowledge, attitude, and perception of parents

\begin{tabular}{|c|c|}
\hline Variable & Value \\
\hline \multicolumn{2}{|l|}{ Knowledge } \\
\hline Heard about epilepsy & $59(96.7)$ \\
\hline \multicolumn{2}{|l|}{ Source of information } \\
\hline Relatives and friends & $23(37.7)$ \\
\hline Internet & $19(31.1)$ \\
\hline Know a person with epilepsy & $53(86.9)$ \\
\hline \multicolumn{2}{|l|}{ Seizures lead to } \\
\hline Jerky movements & $29(47.5)$ \\
\hline Loss of consciousness & $41(67.2)$ \\
\hline Seizures occur at any age & $42(68.9)$ \\
\hline \multicolumn{2}{|l|}{ Causes of seizures } \\
\hline Head injury & $8(13.1)$ \\
\hline Fever & $22(36.1)$ \\
\hline Respiratory distress & $25(41.0)$ \\
\hline Others & $5(8.2)$ \\
\hline Knowledge of the child's diagnosis & $50(82.0)$ \\
\hline \multicolumn{2}{|l|}{ Misconceptions about epilepsy } \\
\hline Mental illness & $32(52.5)$ \\
\hline Contagious diseases & $11(18.0)$ \\
\hline Genetic/hereditary & $14(23.0)$ \\
\hline Evil spirits & $23(37.7)$ \\
\hline Psychological problems & $1(1.6)$ \\
\hline Lowers intelligence & $15(24.6)$ \\
\hline Seizures being fatal or life threatening & $17(27.9)$ \\
\hline \multicolumn{2}{|l|}{ Awareness about safety and injury prevention } \\
\hline Ease the person to the floor & $5(8.2)$ \\
\hline Clear the area around the person & $16(26.2)$ \\
\hline Loosen ties or anything around the neck & $22(36.1)$ \\
\hline Others & $17(27.9)$ \\
\hline $\begin{array}{l}\text { Medicines have to be kept out of reach of } \\
\text { children }\end{array}$ & $27(44.3)$ \\
\hline Worried about side-effects of medication & $27(44.3)$ \\
\hline $\begin{array}{l}\text { Worry about future risks and potential } \\
\text { consequences of seizures }\end{array}$ & $50(82.0)$ \\
\hline Seizures are treatable & $47(77.0)$ \\
\hline Seizures are curable & $45(73.8)$ \\
\hline $\begin{array}{l}\text { Parents know how to perform first aid for } \\
\text { seizures }\end{array}$ & $24(39.3)$ \\
\hline \multicolumn{2}{|l|}{ Parents first response when child has seizures } \\
\hline Loosening cloth around the neck & $22(36.1)$ \\
\hline Removing sharp objects & $17(27.9)$ \\
\hline $\begin{array}{l}\text { Calling a doctor or taking the child to the } \\
\text { hospital }\end{array}$ & $19(31.1)$ \\
\hline Restraining the child during seizures & $48(78.7)$ \\
\hline $\begin{array}{l}\text { Putting object between the teeth during } \\
\text { seizures }\end{array}$ & $54(88.5)$ \\
\hline
\end{tabular}


Table 4. Continued

\begin{tabular}{lc}
\hline Variable & Value \\
\hline Holding a bunch of keys in hand during & $59(96.7)$ \\
$\quad$ seizures & \\
Placing a shoe or an onion on a person's nose & $59(96.7)$ \\
Applying oil on the person during seizures & $59(96.7)$ \\
If follow-up missed, then double dose of & $60(98.4)$ \\
$\quad$ medication is given to the child till the next & \\
$\quad$ follow up & \\
Attitude & \\
Persons with epilepsy can get married & $31(50.8)$ \\
Persons with epilepsy can have children & $39(63.9)$ \\
Allowing their child to marry a person with & $7(11.5)$ \\
epilepsy & \\
Persons with epilepsy can live independent lives & $24(39.3)$ \\
Employing a person with epilepsy & $10(16.4)$ \\
Not willing to work with a person who has & $54(88.5)$ \\
epilepsy & $57(9.8)$ \\
Child with epilepsy being different from children & $56(91.8)$ \\
of his age-group in terms of capability and & \\
talent &
\end{tabular}

Values are presented as number (\%).

worried a lot, and were concerned about their child's life. Around $85.6 \%$ of the parents were angry with God/life, $85.2 \%$ had the 'what-after me' issue, $88.5 \%$ were over-indulgent with their child, 93.4\% found it difficult to entrust their child's care to someone else, and $95.1 \%$ were apprehensive about disclosure of seizures.

\section{Seizure severity affecting knowledge, attitude, and perception of parents of children with epilepsy (Table 5)}

This table depicted that there was a strong positive correlation between parental attitudes and seizure severity $(-0.234 ; p<0.01)$ exhibiting that with an increase in severity of the child's seizures, the scores on parental attitudes also increased thus indicating a negative attitude and vice versa. Seizure severity was positively correlated with perception $(0.203 ; p<0.05)$ indicating that as the severity of the seizures increased, scores on perception also increased thus indicating poor perception.

\section{Case study 1}

"If the child is taken to a baba and gets cured, then the hospital issue is ignored," says Deepa's father.

Deepa, an engaging and spirited fourteen-year-old girl was studying in standard VIII. Her parents were quite excited to talk about her academic achievements. She was referred to a tertiary hospital with symptoms of complex partial seizures and was experiencing one or two episodes once in 10 days lasting for a few seconds. It was an unexpected event for the entire family and the parents were unwilling to accept that the kind of symptoms the girl had could be seizures. Parents' explanatory model was magico-religious and they sought religious treatment influenced by their relatives. The family has spent almost RS50,000 on a faith healer for performing the rituals and ceremonies. Her parents have also tried various methods suggested by relative and friends to control seizures like holding the girl tightly in their arms and reading prayers in her ears during an episode of seizures. A major crisis occurred in the family when after two months of starting treatment and therapy, the girl's father passed away in a road traffic accident. This was an event that had intense repercussion on the family. The family went into a severe financial crunch as the father was the primary breadwinner and after his death, the mother would remain ill most of the time as she was unable to cope with his death. Forced to grow up suddenly due to her mother's illness, father's demise, and lack of support for the family, the girl showed maturity beyond her years. Things came to a further crisis when she attained menarche. They belonged to community where a lot of significance was attached to this milestone in development. Once girls attain menarche, their freedom of movement was very much restricted. It brought many psychosocial and emotional changes in 
Table 5. Seizure severity affecting knowledge, attitude, and perception of parents of children with epilepsy

\begin{tabular}{|c|c|c|c|}
\hline \multirow[b]{2}{*}{ Variable } & \multirow[b]{2}{*}{ Co-related variable } & \multicolumn{2}{|c|}{ Spearman's rho } \\
\hline & & $\begin{array}{l}\text { Correlation } \\
\text { coefficient }\end{array}$ & $p$-value \\
\hline Seizure severity & Toxic side-effects of anti-epileptic medicines & -0.214 & 0.003 \\
\hline Toxic side effects of anti-epileptic medicines & Chronic side-effects of anti-epileptic medicines & $-0.542 *$ & 0.002 \\
\hline Knowledge & Perception & 0.039 & 0.003 \\
\hline Knowledge & Seizure severity & $0.101^{\dagger}$ & 0.000 \\
\hline Attitude & Seizure severity & $-0.234^{\dagger}$ & 0.000 \\
\hline Perception & Seizure severity & $0.203^{*}$ & 0.002 \\
\hline Attitude & Perception & 0.307 & 0.006 \\
\hline
\end{tabular}

High scores on variable perception indicate poor perception.

*Correlation is significant at the 0.05 level (2-tailed).

${ }^{\dagger}$ Correlation is significant at the 0.01 level (2-tailed).

the girl and throughout this period she got support of her mother and elder sister which helped her to cope quite well with those changes.

\section{Case study 2}

"We have "lost" our son, as his life is totally ruined by epilepsy. He cannot be independent and hardly goes out of the house," says Raju's father.

Raju was just over six years, when he came to NIMHANS. When he spoke, his speech was unclear and his parents had to hold him on their lap as he would often fall down while walking. He had continuous drooling from his mouth and needed help to carry out self-care activities. The boy was diagnosed with generalized tonic-clonic seizures and got seizures 12-15 times a day, which lasted for few seconds. He had difficulty in walking and expressing his needs because of his frequent seizures. He was born after 20 years of marriage following several miscarriages. It was evident that there was significant emotional investment from the parents on him as he was the youngest child, who was conceived with great difficulty. To cure him from epilepsy, their village head told the family to perform rituals to honor the family's ancestral spirits, involving performing ceremonies and giving feasts for village elders. The family took a loan of RS75,000 to perform the ceremony but his seizures did not stop. It was apparent that the parents were experiencing a significant emotional crisis about how they would ensure continuity of treatment and medication in the long run as they did not have money to buy medicines and valid documents to avail BPL benefits at the hospital. Parents had come to the tertiary hospital with high expectations that their child would get cured and become normal in terms of mobility and speech. A major marital crisis occurred at the time when the child went 'off his feet' and required to be carried all over the place.

\section{Structure of the guidelines for psychosocial intervention for parents}

A guideline was developed to improve knowledge, attitude, and perception of parents as well as to address the socio-cultural barriers to treatment that was based on the ethno-centric perspective. This perspective states that ethnic and cultural values affect a person's perception of health, reaction to illness, treatment-seeking behavior, and trust in the treatment process. So, it was important to take into consideration social, cultural, and psychological factors that may influence parents' response to the management of epilepsy. The guidelines identified important issues that medical practitioners should focus on: Praise the family's handling of the situation so far; Encourage family members to vent their concerns, fears and difficulties encountered in managing their child's illness; Emotional support needs to be provided to parents throughout the treatment process by normalizing their feelings and validating their concerns. They need information and support especially when faced with difficult decisions such as whether new treatment options (e.g., surgical treatment should be explored) that may seem terrifying to them; Assess the alternative healing practices that have been utilized by the family as some practices involve herbs and ayurvedic treatments that may counteract the prescribed medicines; The family will be reluctant to disclose that they are trying alternative treatment modalities in fear of being judged as 'backward' by the medical practitioner. Respect the choices made by the family and support these remedies unless they are contraindicated or harmful; Explore the family's understanding about epilepsy. Thereafter, educate them about epilepsy by 
using the medical model, giving statistical data, and the biological causes of illness. Make sure to refute moral or religious causes of epilepsy; Address parents' myths and misconception about epilepsy, its causes, and consequences; Educate them about what can trigger seizures, side-effects of anti-epileptic medicines, safety and injury prevention measures, how seizures could affect their child's learning, and how the family could help by employing a positive parenting style; Ask the family to share their understanding of the information provided; Parents' reaction to their child's illness sets the stage for the child's own interpretation of its significance. So, parents should be provided with information regarding disclosure about epilepsy to the child - when and how to do it.

Dos and don'ts for medical practitioners: Communicate in a simplified manner without using medical jargon; Encourage the family to ask questions; Information has to be disseminated in a language preferred by the family members. If not fluent in that language, refer to a colleague; Do not ridicule the family for spending money on religious treatment; Cultural sensitivity and a non-judgmental attitude are two pre-requisites for effective therapeutic relationships; Ensure confidentiality by reiterating it again and again, throughout the interview and intervention process.

\section{Discussion}

Children are at a higher risk of developing difficulties and disorders that co-occur along with epilepsy and affect their psychological, social, and cognitive development. ${ }^{11}$ Febrile seizures are easily controlled with medications ${ }^{12}$ but seizures that occur at quite a young age due to pre or peri-natal complications often result in delaying the child's developmental milestones. These manifest in the form of co-morbid conditions like IDD and attention deficit hyperactivity disorder ${ }^{13}$ that are consistent with the present study's findings. The current research also showed that seizures had not been controlled in $73.3 \%$ of the children, mostly those whose neonatal seizures had resulted in delaying development of motor, social, cognitive or speech milestones. One of the studies has highlighted that poorly controlled seizures may be disabling, and could interfere with the child's ability to learn and become a hindrance to normal growth and development, whereas secondary factors, such as negative beliefs about epilepsy could make the child feels socially more isolated. $^{14}$

One of the studies states that parents of children with epilepTasy and co-morbid conditions were emotionally overwhelmed because their seizures were not being controlled with medication and were more severe in terms of frequency and duration of episodes. Uncertainty of their child's seizures had led the parents to be constantly vigilant and they experienced more negative emotions such as feeling sad, helpless, or anxious on witnessing their child's seizure episodes. Mostly, in desperation they shifted to religio-spiritual treatment as a cure for their child's illness. ${ }^{15}$

The western model of epilepsy management may not apply to a developing country like India where adaptation to, and adoption of, treatment strategies for epilepsy can be understood from a socio-cultural perspective. In India, traditional healers were more likely to be consulted as it was more acceptable, less costly, payment could be made in installments or through alternative means, and there were no side-effects. Studies have shown that faith-healers devoted more time to explaining the symptoms, causes, and treatments. They were more cordial compared to physicians or medical practitioners and the family participated more actively in the healing process by asking and answering questions and physically performing rituals. ${ }^{16,17}$

Religion has a significant impact on society and temple healing practices are highly acceptable by all sections of society. Rituals and prayers accompanied by practices like fasting, eating raw fruits, and praying for regular periods was widely used during the initial period of illness. ${ }^{18}$ In the present study, $72.1 \%$ parents had approached faith healers or holy men for consultation as a complement to medical treatment and $91.8 \%$ visited holy places, worshipped for several hours each day, and performed "mannat" to treat their child's seizures. One of the interesting findings of this study was that such treatments were viewed as complementary rather than as an alternative to western medication. Spirituality or faith or prayers were reported as a way of coping with the uncertainty of their child's illness and in desperation most of these parents turned to religious treatments for a cure, often under the influence of their families. Similar findings were reported in previous studies which discussed how religion influenced common beliefs about epilepsy and parents' perception. Rituals and prayers were performed to ask for forgiveness from God and cleanse the body and soul of child from evil and make it pure again. ${ }^{16,18}$

Every culture develops its own meanings and supporting systems to make sense of diseases (e.g., knowledge, beliefs, customs, rituals, and symbols). Beliefs about epilepsy and misconceptions about the etiologies of seizures affect treatment choices made by family members and persons with epilepsy. ${ }^{5}$ In the present study, $98.4 \%$ parents had misconceptions regarding the consequences of missing a pre- 
scribed anti-epileptic medicine dose or follow-up date in the hospital that was due to parents' poor knowledge and understanding of their child's epilepsy. One of the studies highlighted that medical treatment misconceptions affected the parents' ability to manage their children's illness. When parents' confidence is low, it negatively affects the children's perception about illness as they learn by observing their parents' reaction, and as a result when these children grow into adults, it affects their ability to manage their own condition. ${ }^{18}$

The present study reported that watching their child's seizures often left parents helpless, and not knowing what to do at that point of time, they engaged in faulty practices like giving a bunch of keys or putting objects in the mouth that were ineffective in controlling the seizures or making the child feel better or at ease, during an episode. All these methods adopted by parents depended upon the type and severity of seizures. One of the studies discussed that during seizures since parents get scared and anxious, they would try to stop the seizures by adopting strategies that could be harmful and even dangerous for the child though their intention was not to hurt the child but rather to protect from an injury that could be caused due to seizures. $^{17}$

The current study found that the majority of parents were unaware about safety and injury prevention and how to perform first aid measures during seizures. This could be due to their panic reaction that made them act on impulse, and also led to their forgetfulness and not practicing first aid measures at the time of their child's seizures. One of the studies has concluded that parents' knowledge of safety measures and practices was very low and it did not improve even after they were educated on effective strategies to be adopted for safety and injury prevention because they lacked practical skills. ${ }^{18}$ Above all, these findings could also point towards ineffectiveness of methodology used for providing information to the parents that was not explored by the researcher in the present study.

The maximum number of parents in the present study believed that persons with epilepsy could not live an independent life, or get married, or have children and required more social and practical support. Parental attitudes towards epilepsy were also related to poor outcome of epilepsy in children and uncertainty of seizures and safety concerns as someone always had to be in proximity to the affected child. The current findings showed that the parents' negative attitude towards epilepsy appeared to be also reinforced by cultural beliefs that epilepsy was caused by evil spirits or mental illness and was genetic. The perception of parents who lacked formal education and stayed in rural areas was colored with more such firm beliefs and they had difficulty in understanding the medical model of epilepsy. Multiple studies have reported similar findings. ${ }^{19,20}$ The above findings in the present study urges professionals to remember that since clients come with varying degrees of knowledge, experience with the disease, and misinformation; when addressing caregivers concerns, importance should always be given to their cultural beliefs.

The study also reported, that some of the parents, mostly mothers whose children had co-morbid condition considered themselves responsible for their child's epilepsy since they felt that during pregnancy, the child might have developed some infection or the child's brain did not develop properly. As professionals, it is important to remember that the parents' emotional experience was an important component of the care giving process. Since mothers view their child as an extension of themselves, they are more emotionally attached to their child and this was consistent with the findings of a study done to assess mothers' reactions to their child's diagnosis.

One of the important points highlighted by this study was that the parents' perception of their child's epilepsy directly affected their psychological well-being and feelings of guilt, inadequacy and helplessness on seeing their child in pain and not being able to help. Factors like total number of medications taken, number of visits to a doctor in the previous year, and number of nights spent in hospital were related to seizure frequency and were consistent with the findings of a study to explore the impact of epilepsy on family life. ${ }^{9}$

The current study also found that the majority of parents were emotionally overwhelmed and angry with God for making their child suffer, and seemed to be in a stage of grief. The parents expecting their child to "grow out of the disability", or having unrealistic hopes on the extent to which their child would attain a normal life in spite of the disability were consistent with the findings of previous studies. ${ }^{20-23}$ One of the studies states that social control is often exerted through shame and guilt. The family has to maintain an ideal image to the outside world: an image of having a perfect family, a perfect life, and a perfect home. If family members fail to meet this societal expectation, they have feelings of shame and guilt and keep hoping that their child will grow normally and exert the same pressure on the child that also affects parent-child interaction and their relationship. $^{24}$

Multiple studies have highlighted the need for sensitization programs for better management of seizures at home. ${ }^{25-27}$ These sensitization programs need not be at community level but doctors can create awareness even at the hospital by educating family members about epilepsy, addressing their myths and misconceptions that 
would also improve treatment adherence and compliance. One of the studies stated that it was important to recognize and incorporate family members' former beliefs and practices into the treatment plan rather than wasting time and energy in trying to change their beliefs and health practices. So, awareness and sensitization programs need to take into consideration culturally perceived causes for epilepsy since family members' perception was affected by their cultural beliefs, religious beliefs, and the community's attitude toward individuals with epilepsy. $10,28,29$

At the end of the current study, a guideline was prepared that was developed from an ethno-centric perspective that takes into consideration the personal and social experience of illness and states that cross-cultural differences between health-care providers and clients can affect therapeutic relationships. ${ }^{27,30,31}$ One of the studies states that clinicians need to negotiate between various models of illness as it affects the treatment seeking behavior of clients and their family members and is an important step in involving client and family members in treatment, promoting compliance, evaluating treatment outcomes, and reducing their dissatisfaction. ${ }^{32}$

\section{Limitations and implication for future research}

Some of the constraints in generalizing this study's findings are small sample size, its being cross-sectional in nature, time constraints, and sampling bias. The questionnaire developed to assess parents' knowledge, attitude, and perception is in the process of validation and further studies are needed to establish its psychometric properties.

The present study's results would help to develop interventions by keeping in mind the social ecological model. The model states that there is a reciprocal relationship between children with epilepsy and the systems surrounding them like family, school, peers, health care providers, and the cultural systems. The guidelines prepared for addressing socio-cultural barriers would be further validated and tested for efficacy.

From a community organization and social action perspective, there is a need to mobilize support from different stakeholders such as NGOs, community-based organizations, community leaders, and policy makers who can act as change agents to sensitize the general public by addressing the myths and misconception related to epilepsy and community-based treatment and rehabilitation programs in rural areas.

Parents' negative attitudes and poor perception cannot be entirely attributed to epilepsy as most of these children had co-morbid con- ditions that led to poor outcome in the form of impairment in their daily living activities, behavioral problems, as well as poor psychological and social development. There is a need for cross-cultural accommodation where health care providers involve client and family members in the treatment by taking into consideration socio-cultural and medical factors for illness description, management plans, and follow-up activities. A management plan for addressing socio-cultural barriers to treatment that affect parents' knowledge, attitude and perception towards epilepsy should incorporate culturally sensitive practices by clinicians, understand parents' religious and spiritual values, be able to empathize, respect, and appreciate the efforts made by family members to cope with chronicity of the child's illness, sense of helplessness, and feelings of guilt for failing as a parent.

\section{Conflicts of Interest}

The authors declare that they have no conflicts of interest.

\section{References}

1. Santhosh NS, Sinha S, Satishchandra P. Epilepsy: Indian perspective. Ann Indian Acad Neurol 2014;17(Suppl 1):S3-11.

2. Gadgil P, Udani V. Pediatric epilepsy: the Indian experience. J Pediatr Neurosci 2011;6(Suppl1):S126-9.

3. Dung $A D$, Singh $H K$, Kumari $S$, Gupta $M$, Raval $M$, Rajender $G$. Knowledge, attitude and perception of caregivers of children with epilepsy. Delhi Psychiatry Journal 2009;12:274-5.

4. Gambhir SK, Kumar V, Singhi PD, Goel RC. Public awareness, understanding \& attitudes toward epilepsy. Indian J Med Res 1995;102:34-8.

5. Ekeh BC, Ekrikpo UE. The knowledge, attitude, and perception towards epilepsy amongst medical students in Uyo, Southern Nigeria. Adv Med 2015;2015:876135.

6. Suryakantha AH. Nutrition \& Health. In: Suryakantha AH, ed. Community medicine with recent advances. New Delhi: Jaypee Brothers, 2014; 204-15.

7. Gourie-Devi M, Singh V, Bala K. Knowledge, attitude and practices among patients of epilepsy attending tertiary hospital in Delhi, India and a review of Indian studies. Neurology Asia 2010;15:225-32.

8. Ogunniyi A, Osuntokun BO. Epidemiology of neurologic illnesses in Africa. In Proceedings of the Tropical Neurology Symposium at the Joint Meeting of the World Federation of Neurology with the Royal Society of Tropical Medicine and Hygiene. Nigeria: Wemilore Press Nig Ltd., 1993.

9. Hirfanoglu T, Serdaroglu A, Cansu A, Soysal AS, Derle E, Gucuyener K. Do knowledge of, perception of, and attitudes toward epilepsy affect the quality of life of Turkish children with epilepsy and their parents? Epilepsy Behav 2009;14:71-7. 
10. Camfield C, Breau L, Camfield P. Impact of pediatric epilepsy on the family: a new scale for clinical and research use. Epilepsia 2001;42:104-12.

11. Hall-Parkinson D, Tapper J, Melbourne-Chambers R. Parent and caregiver knowledge, beliefs, and responses to convulsive seizures in children in Kingston, Jamaica - a hospital-based survey. Epilepsy Behav 2015;51:306-11.

12. Gzirishvili N, Kasradze S, Lomidze G, et al. Knowledge, attitudes, and stigma towards epilepsy in different walks of life: a study in Georgia. Epilepsy Behav 2013;27:315-8.

13. Seidenberg M, Pulsipher DT, Hermann B. Association of epilepsy and comorbid conditions. Future Neurol 2009;4:663-8.

14. Carpay HA, Arts WF, Vermeulen J, et al. Parent-completed scales for measuring seizure severity and severity of side-effects of antiepileptic drugs in childhood epilepsy: development and psychometric analysis. Epilepsy Res 1996;24:173-81.

15. Wagner JL, Smith G, Ferguson P, van Bakergem K, Hrisko S. Pilot study of an integrated cognitive-behavioral and self-management intervention for youth with epilepsy and caregivers: Coping Openly and Personally with Epilepsy (COPE). Epilepsy Behav 2010;18:280-5.

16. Russ SA, Larson K, Halfon N. A national profile of childhood epilepsy and seizure disorder. Pediatrics 2012;129:256-64.

17. Desai P, Padma MV, Jain S, Maheshwari MC. Knowledge, attitudes and practice of epilepsy: experience at a comprehensive rural health services project. Seizure 1998;7:133-8.

18. Sureka RK, Sureka R. Knowledge, attitude, and practices with regard to epilepsy in rural north-west India. Ann Indian Acad Neuro/ 2007;10:160-4.

19. Hughes RS. An investigation of coping skills of parents of children with disabilities: implications for service providers. Education and Training in Mental Retardation and Developmental Disabilities 1999:34:271-80.

20. Ismail H, Wright J, Rhodes P, Small N. Religious beliefs about causes and treatment of epilepsy. Br J Gen Pract 2005;55:26-31.

21. Shore CP, Buelow JM, Austin JK, Johnson CS. Continuing psychosocial care needs in children with new-onset epilepsy and their parents. J Neurosci Nurs 2009;41:244-50.

22. Chiabi A, Nguefack S, Monkam RT, Enoh J, Nguefack F. Practices of mothers towards infant seizures in Yaounde, Cameroon. JMR 2018;4:102-5.

23. Svraka E, Loga S. Cerebral palsy and epilepsy in children. Med Arh 2005;59:188-90.

24. Njamnshi AK, Angwafor SA, Tabah EN, Jallon P, Muna WF. General public knowledge, attitudes, and practices with respect to epilepsy in the Batibo Health District, Cameroon. Epilepsy Behav 2009;14:83-8.

25. Gazibara T, Nikolovski J, Lakic A, Pekmezovic T, Kisic-Tepavcevic D. Parental knowledge, attitudes, and behaviors towards children with epilepsy in Belgrade (Serbia). Epilepsy Behav 2014;41:210-6.

26. Marvin RS, Pianta RC. Mothers' reactions to their child's diagnosis: relations with security of attachment. Journal of Clinical Child Psychology 1996;25:436-45.

27. Wo SW, Ong LC, Low WY, Lai PSM. Exploring the needs and challenges of parents and their children in childhood epilepsy care: a qualitative study. Epilepsy Behav 2018;88:268-76.

28. Sawyer SM, Drew S, Yeo MS, Britto MT. Adolescents with a chronic condition: challenges living, challenges treating. Lancet 2007;369:1481-9.

29. Majid SR. Wheels within a wheel: An ethnocultural perspective on South Asian families with childhood chronic illness. San Francisco Bay: Flamingo, 2003;5527-32.

30. Groce NE, Zola IK. Multiculturalism, chronic illness, and disability. Pediatrics 1993;91(5 Pt 2):1048-55.

31. Putsch III RW, Joyce M. Dealing with patients from other cultures. In: Editor NAME, ed. Clinical Methods: the History, Physical, and Laboratory Examinations. 3rd ed. Boston: Butterworths, 1990;229-31.

32. Kleinman A, Eisenberg L, Good B. Culture, illness, and care: clinical lessons from anthropologic and cross-cultural research. Ann Intern Med 2006:88:251-8. 